
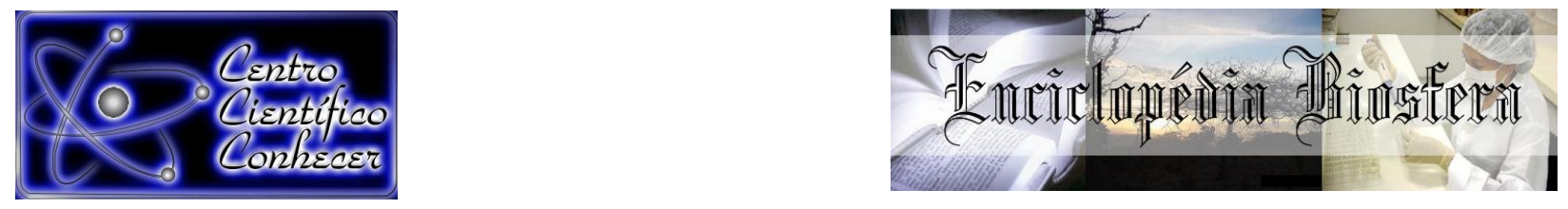

\title{
ASSEPSIA, DESINFESTAÇÃO E ISOLAMENTO IN VITRO DE PROPÁGULOS DE BAMBU COM USO DE PRODUTO NATURAL
}

\footnotetext{
Débora Cristina Pereira Prado ${ }^{1}$, Fernando Rusch ${ }^{2}$

${ }^{1}$ Mestre em Ciências Florestais - Universidade Estadual do Centro-Oeste, Irati, Brasil.

${ }^{2}$ Doutorando em Ciências Florestais - Universidade Estadual do Centro-Oeste, Irati, Brasil.

(fe_rusch@yahoo.com.br)
}

Recebido em: 06/04/2018 - Aprovado em: 10/06/2018 - Publicado em: 20/06/2018 DOI: 10.18677/EnciBio_2018A11

\begin{abstract}
RESUMO
O bambu tem um grande potencial de uso e aplicações, desde construções civis a alimentação humana. É uma gramínea de ampla distribuição geográfica e fácil adaptabilidade aos diversos tipos de ambiente. Sua multiplicação vegetativa é a forma mais comum de propagação, sendo a micropropagação uma opção para a produção em escala comercial desta super gramínea. Porém a contaminação microbiana apresenta-se como um entrave a esta forma de multiplicação. $O$ presente trabalho avaliou a origem do explante (gema axilar ou segmento nodal), concentrações de BAP (2, 3 e $\left.4 \mathrm{mg} \cdot \mathrm{L}^{-1}\right)$ e a utilização de óleo essencial de Mentha arvensis no controle da contaminação in vitro. Os explantes oriundos de gemas axilares apresentaram menor oxidação e contaminação, o meio com concentração de $3 \mathrm{mg} \cdot \mathrm{L}^{-1}$ de BAP foi mais favorável ao estabelecimento da cultura e o óleo essencial de $M$. arvensis foi eficaz no controle da contaminação fúngica $e$ bacteriana.
\end{abstract}

PALAVRAS-CHAVE: Contaminação fúngica e bacteriana, Mentha arvensis, micropropagação.

\section{ASSEPSIA, DISINFESTATION AND IN VOLATILE INSULATION OF BAMBOO PROPAGATES WITH NATURAL PRODUCT USE}

\begin{abstract}
Bamboo has a great potential of use and applications, from civil constructions to human feeding. It is a grass of wide geographical distribution and easy adaptability to the different types of environment. Its vegetative multiplication is the most common form of propagation, with micropropagation being an option for the commercial scale production of this super grass. However, microbial contamination is an obstacle to this form of multiplication. The present work evaluated the origin of the explant (axillary bud or nodal segment), BAP concentrations (2, 3 and 4 mg.L-1) and the use of Mentha arvensis essential oil in the control of in vitro contamination. The explants from axillary buds presented lower oxidation and contamination, the medium with concentration of $3 \mathrm{mg} . \mathrm{L}-1$ of BAP was more favorable to the establishment of the culture and the essential oil of $M$. arvensis was effective in the control of fungal and bacterial contamination.
\end{abstract}

KEYWORDS: Fungal and bacterial contamination, Mentha arvensis, micropropagation. 
A crescente demanda por madeira e a necessidade de reduzir o processo de desmatamento têm estimulado a busca por novas alternativas para o suprimento deste recurso. Uma alternativa que surge é a utilização de bambu, planta considerada como uma 'madeira ecológica' ou 'madeira do futuro', por apresentar diversos usos e aplicações. Este material se apresenta como um recurso renovável, de rápido crescimento e elevada produtividade por área (CHAOWANA , 2014), além de ser um excelente sequestrador de carbono.

O bambu, em termos científicos, é classificado como representante da família das Gramíneas (Gramineae ou Poaceae), Subfamília Bambusoideae que é dividida em três tribos, sendo que os denominados Arundinarieae e Bambuseae, são os de maior porte e xilemáticas, ou seja, com colmos lenhosos, respectivamente de clima temperado e tropical e o Olyreae, de menor porte, no caso, herbáceos (YEASMIN et al., 2014; CLARK et al., 2015; SORENG et al., 2015). O bambu, basicamente é uma gramínea tubular, composta por uma mistura de lignina e holocelulose (hemicelulose e celulose), organizada em feixes de fibras, células parenquimatosas e vasos condutores.

Atualmente, se estimam a existência de 119 gêneros com 1.482 espécies de bambu no mundo (CLARK et al., 2015). Dessas espécies, em torno de $65 \%$ são originárias da Ásia, $28 \%$ das Américas e $7 \%$ da África. No Brasil ocorrem 258 são espécies nativas, sendo que dessas, 175 são consideradas endêmicas (FILGUEIRAS; VIANA, 2017). O bambu adapta-se a diferentes altitudes, desde ao nível do mar até superiores a 4.000 metros, climas diversificados, seja úmido, semiárido, tropical ou subtropical. Além desta ampla ocorrência, destaca-se por possibilitar colheita anual, desde que se mantenha os brotos e hastes mais jovens, evita que se modifique o meio ambiente, tanto que nem se percebe que ocorreu a colheita no local, evitando assim danos ambientais, como por exemplo a erosão (LU et al., 2018).

O bambu é uma planta que apresenta elevada importância e interesse, porém em muitos casos, de difícil propagação (RIBEIRO et al., 2016). Embora possa ser multiplicado de forma sexuada, esta é de difícil execução, pois muitas espécies de bambu levam décadas para gerarem sementes (BAREJA, 2010). Portanto, as técnicas de micropropagação constituem-se numa alternativa para a multiplicação e produção comercial do bambu (TORRES, 2016), contudo a contaminação ainda é um entrave para o cultivo in vitro do bambu (SINGH et al., 2012). Para vencer este obstáculo, pode-se optar por explantes menores, que oferecem maior chance de se obter uma cultura sem contaminação (BRUNO, 2017).

Além da origem e tamanho do explante como forma de obtenção de culturas in vitro com menor contaminação, produtos antimicrobianos no meio de cultivo têm sido utilizados como forma de obter culturas livres de contaminação (PEREIRA et al., 2015). A Mentha arvensis (hortelã) é uma planta medicinal, com baixo impacto ambiental e potencial para controle de fitopatógenos (GADELHA et al., 2003; SOKOVI'C et al., 2009) o que a torna uma opção para o controle de contaminações na cultura de tecidos vegetais in vitro. Ante o exposto, o presente trabalho teve como objetivo avaliar a eficácia em um processo de assepsia, desinfestação e isolamento in vitro de propágulos de bambu com a utilização de produto fungicida e bactericida natural para a micropropagação.

\section{MATERIAL E MÉTODOS}


Os experimentos foram conduzidos em Julho de 2017, no Laboratório de Silvicultura, lotado no Departamento de Engenharia Florestal da Universidade Estadual do Centro-Oeste (UNICENTRO), Campus de Irati, Paraná. As brotações utilizadas como fontes de propágulos para os explantes, foram provenientes de touceira, sem tratamento prévio ou manejo pré-definido, localizada neste campus.

Para a coleta das brotações, foi utilizada tesoura de poda previamente esterilizada em álcool $70 \%$ (v/v), sendo acondicionadas em caixa de isopor contendo solução aquosa de ácido ascórbico a $0,1 \%(\mathrm{~m} / \mathrm{v})$. Em seguida, foram transportadas ao Laboratório de Silvicultura da UNICENTRO, onde foi realizada a assepsia dos propágulos, para estabelecimento dos explantes in vitro e demais experimentos para desinfestação e isolamento.

No laboratório, os colmos coletados foram transferidos para erlenmeyer e submetidos a lavagem com água corrente e detergente, tendo as regiões de gemas axilares cuidadosamente esfregadas com escova de cerda macia, e suas bainhas foliares removidas. Posteriormente o material foi submetido a três sucessivos enxágues em água.

$\mathrm{Na}$ capela de fluxo laminar, os colmos foram submetidos a desinfestação, e mantidos imersos em solução aquosa de $1 \%$ de $\mathrm{NaOCl}$ por 25 minutos, havendo agitação esporádica. Após o tempo de permanência, os colmos foram submetidos a três enxágues sucessivos em água desionizada autoclavada, permanecendo imersos em água até o isolamento nos tubos de ensaio.

Utilizando-se pinça e bisturi, foram confeccionados explantes, de segmentos nodais de aproximadamente um $\mathrm{cm}$ de comprimento e gemas axilares excisadas. Estes foram individualmente introduzidos em tubos de ensaio de $25 \times 150 \mathrm{~mm}$, contendo $10 \mathrm{~mL}$ de meio nutritivo MS (MURASHIGE; SKOOG, 1962), acrescido de $3 \%$ de sacarose, $0,01 \%$ de mioinositol. Como gelificante do meio, foi utilizado $0,65 \%$ de ágar $V_{e t e c}{ }^{\circledR}$, fundido em forno de micro-ondas e adicionado ao meio antes da esterilização em autoclave.

Ao meio foram adicionadas 2, 3 e $4 \mathrm{mg} \cdot \mathrm{L}^{-1}$ de BAP (6-benzilaminopurina), tanto para os tratamentos com gemas axilares como com segmento nodal (T1 até T6). Também foram implementados outros dois tratamentos (T7 e T8), sendo um para gemas axilares e outro para segmentos nodais, com $3 \mathrm{mg} \cdot \mathrm{L}^{-1}$ BAP e a incorporação de $0,25 \%(\mathrm{v} / \mathrm{v})$ de óleo essencial de $M$. arvensis.

Em seguida, o $\mathrm{pH}$ do meio foi ajustado para 5,7 $\pm 0,1$ com solução de $\mathrm{NaOH}$ $\left(1 \mathrm{~mol} . \mathrm{L}^{-1}\right)$ e de $\mathrm{HCl}\left(1 \mathrm{~mol} . \mathrm{L}^{-1}\right)$, para então ser esterilizado em autoclave $\left(121^{\circ} \mathrm{C}\right.$ e 1,1 atm de pressão) por 20 minutos, previamente a inoculação dos propágulos. Após a inoculação dos explantes no meio de cultura, os tubos de ensaio foram vedados com tampas de polipropileno, conforme Figura 1. 

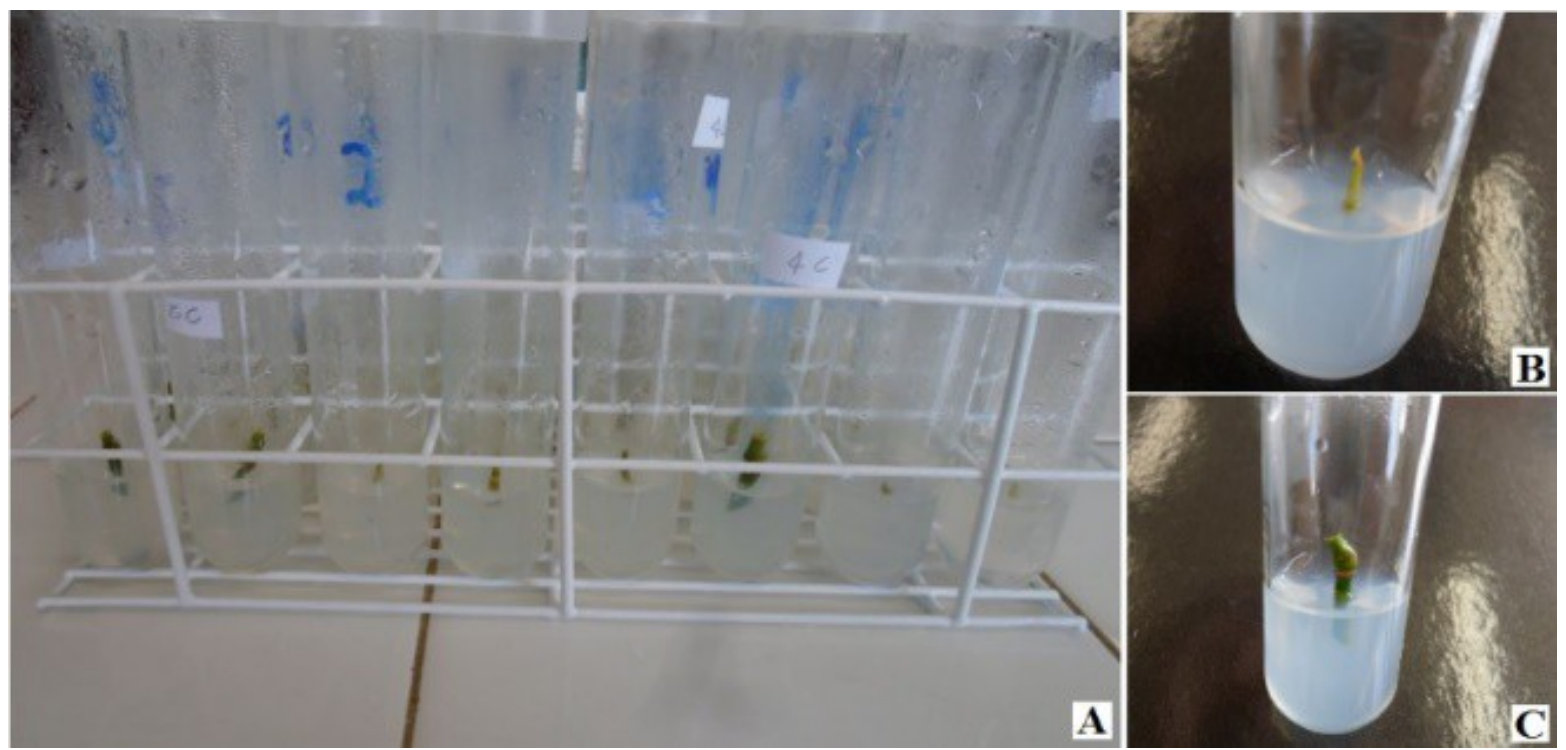

FIGURA 1. Experimento realizado. Ilustração dos tratamentos $(A)$; tubo de ensaio com amostra de gema axilar (B); tubo de ensaio com amostra de segmento nodal (C).

As culturas foram mantidas em sala de crescimento a temperatura de $25 \pm 2$ ${ }^{\circ} \mathrm{C}$, sob fotoperíodo de 16 horas de luz e oito horas de escuro, com irradiância de 11 $\mu \mathrm{mol} \mathrm{m} \mathrm{m}^{-2} \mathrm{~s}^{-1}$ obtida por lâmpadas frias brancas fluorescentes. As avaliações foram feitas semanalmente, até os 21 dias após o isolamento dos explantes, com base nas variáveis: oxidação fenólica, contaminação por fungos e bactérias, a sobrevivência dos explantes indução de gemas axilares.

O delineamento utilizado foi o inteiramente casualizado com cinco repetições, constituídas por dois tubos de ensaio contendo um propágulo por tubo. Os dados obtidos foram verificados quanto a homogeneidade de variância e quando pertinente, as médias comparadas pelo Teste de Duncan, ao nível de $5 \%$ de probabilidade de erro. Para as variáveis oxidação e sobrevivência foi realizada a análise de correlação de Pearson, sendo posteriormente realizada análise de regressão, a fim de identificar o ponto crítico em que a oxidação conduz a necrose e morte dos explantes. Os softwares utilizados para análise dos dados foram o Assistat 7.7 e o Microsoft Excel 2010.

\section{RESULTADOS E DISCUSSÃO}

Observou-se que o processo de oxidação teve início logo na primeira semana após o isolamento dos explantes, bem como a contaminação fúngica e bacteriana. Nos tratamentos com adição de óleo essencial de $M$. arvensis no meio de cultivo, não foi constatada contaminação fúngica e nem bacteriana, nesta avaliação inicial.

Aos 14 dias o processo de oxidação ocorreu na maioria dos explantes, com muitos parcialmente escurecidos. Não foi constatada contaminação bacteriana no tratamento T7, nem fúngica no T7 e T8, os quais continham em sua composição óleo essencial de $M$. arvensis. Observou-se a indução de apenas uma brotação, esta no T6 (explante de segmento nodal), apresentando cerca de $1,5 \mathrm{~cm}$ de comprimento.

$\mathrm{Na}$ avaliação aos 21 dias, a maioria dos explantes já haviam se oxidado por completo. A contaminação fúngica permaneceu ausente nos tratamentos T7 e T8 e a bacteriana no tratamento T7 (Tabela 1). Na única brotação obtida apontada na avaliação anterior houve necrose provocada pela oxidação fenólica. 
TABELA 1. Contaminação fúngica e bacteriana em segmentos nodais e gemas axilares de bambu submetidos a tratamentos de assepsia no isolamento e indução in vitro, aos 21 dias após a inoculação em meio de cultivo.

\begin{tabular}{ccccc} 
Tratamentos $^{*}$ & Fúngica (\%) & \multicolumn{2}{c}{ Bacteriana (\%) } \\
\hline T1 2G & 80 & ab & 20 & bc \\
T2 2C & 100 & $\mathrm{a}$ & 30 & $\mathrm{ab}$ \\
T3 3G & 30 & $\mathrm{c}$ & 60 & $\mathrm{a}$ \\
T4 3C & 100 & $\mathrm{a}$ & 30 & $\mathrm{ab}$ \\
T5 4G & 70 & $\mathrm{~b}$ & 60 & $\mathrm{a}$ \\
T6 4C & 100 & $\mathrm{a}$ & 40 & $\mathrm{ab}$ \\
T7 3OG & 0 & $\mathrm{~d}$ & 0 & $\mathrm{c}$ \\
T8 3OC & 0 & $\mathrm{~d}$ & 30 & $\mathrm{ab}$ \\
\hline CV\% & 59,13 & & 72,92 & \\
\hline
\end{tabular}

2, 3 e 4 = doses de BAP em mg. L $^{-1} ; \mathrm{G}=$ explantes confeccionados de gemas axilares excisadas; $\mathrm{C}=$ explantes confeccionados de segmento nodal; $\mathrm{OG}$ ou $\mathrm{OC}=\mathrm{com}$ adicao de óleo essencial de $M$. arvensis ao meio de cultivo, para as gemas axilares (G) e segmento nodal (C). Valores seguidos da mesma letra não diferem significativamente pelo teste de Duncan para contaminação fúngica $(p<0,0001)$ e para contaminação bacteriana $(p<0,02)$.

O óleo essencial de $M$. arvensis demonstrou potencial para controle de fungos e bactérias em cultivo in vitro, fato confirmado pela ausência de contaminação nos tratamentos T7 e T8 (Tabela 1). Este resultado reforça o resultado obtido por Gadelha et al. (2003), os quais atestam a eficiência deste óleo essencial no controle da infestação de fungos fitopatogênicos. Contudo, todos os explantes isolados em meio de cultivo contendo este óleo essencial apresentaram oxidação logo na primeira avaliação, aos sete dias, culminando na morte dos explantes.

O tratamento T3 $3 G$ foi o tratamento que apresentou menor contaminação fúngica com explantes sobreviventes nas primeiras avaliações do experimento. Ribeiro et al. (2016), constataram que a sacarose no meio de cultivo contribuiu para maior contaminação da cultura in vitro de Bambusa vulgaris, o que pode ter contribuído para a alta contaminação com fungos no cultivo dos explantes. Altas taxas de contaminação (acima de $50 \%$ ) também foram relatadas em experimentos de isolamento in vitro de diferentes espécies de bambu realizados por Araujo et al. (2015).

Com relação a contaminação bacteriana, o tratamento $T 12 \mathrm{G}$ foi o que apresentou menor contaminação, com explantes sobreviventes nas primeiras avaliações do experimento. Observou-se, portanto, que nos tratamentos em que foram utilizados como explantes as gemas axilares, houveram menor contaminação fúngica e bacteriana. Para analisar estatisticamente a correlação entre a oxidação e a mortalidade dos explantes, neste experimento, procedeu-se a análise de correlação de Pearson, esta confirmou a influência negativa $(r=-0,9471)$ da oxidação para a sobrevivência dos explantes (Figura 2). 


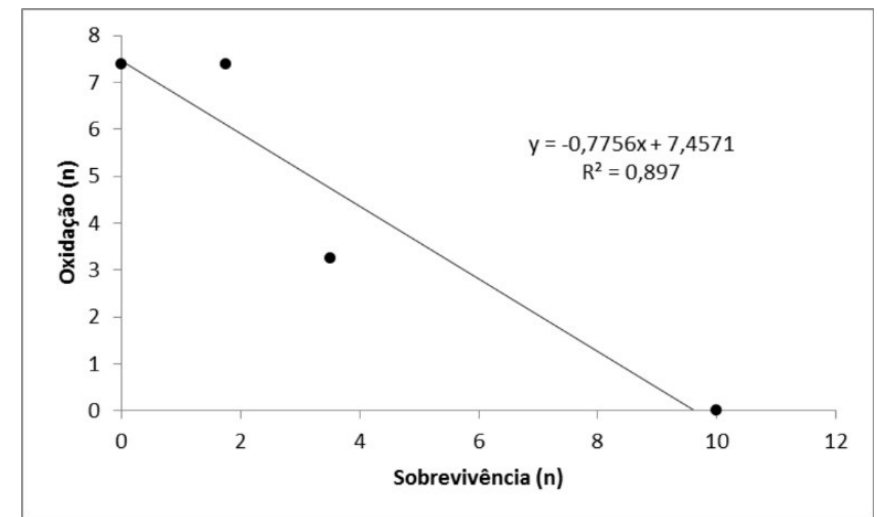

FIGURA 2. Correlação de Pearson entre a oxidação fenólica e a sobrevivência média dos explantes de bambu in vitro, submetidos a desinfestação em óleo essencial de $M$. arvensis, avaliada aos 21 dias de cultivo.

O ajuste de um modelo de regressão para as variáveis oxidação e mortalidade em relação ao tempo permitiu uma análise gráfica (Figura 3) da interação entre a oxidação e a mortalidade dos explantes, ao longo dos 21 dias, para cada tratamento, o que possibilitou identificar o momento para transferência do explante para outro meio de cultivo ou outra intervenção no sentido de minimizar o efeito da oxidação fenólica e evitar a necrose.

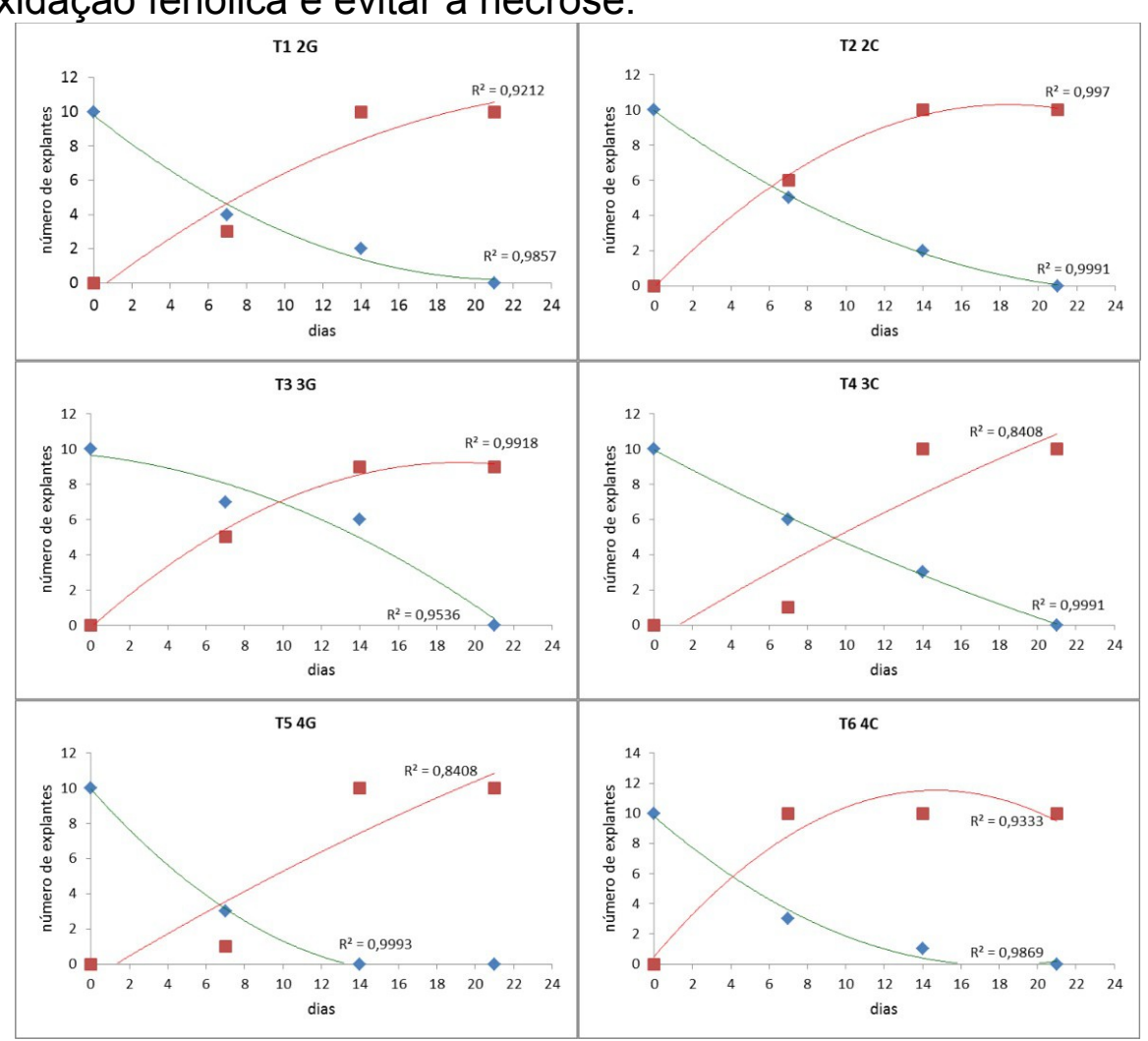

Figura 3. Gráficos de oxidação e mortalidade ao longo dos 21 dias do experimento.

- = Sobrevivência; = Oxidação; Na coluna da esquerda, encontram-se os gráficos dos tratamentos em que os explantes são as gemas axilares (G) e na coluna da direita, os gráficos dos tratamentos em que os explantes são os segmentos nodais $(C)$. 
Observou-se que tanto para os explantes oriundos de gemas axilares como dos segmentos nodais o tratamento com $3 \mathrm{mg} \cdot \mathrm{L}^{-1}$ de BAP no meio de cultivo teve o maior intervalo de tempo entre a instalação do experimento e o momento crítico em que o número de explantes oxidados supera o número de explantes não oxidados (próximo de 10 dias), indicando que a oxidação dos explantes foi mais lenta, sendo portanto, o meio de cultivo com $3 \mathrm{mg} \cdot \mathrm{L}^{-1}$ de BAP, o mais indicado entre as demais concentrações testadas (Figura 2). Waikhom e Louis (2014) constataram que para as espécies $B$. tulda e $M$. baccifera, a concentração mais eficaz para o processo de propagação, foi de $3 \mathrm{mg} \cdot \mathrm{L}^{-1}$ de BAP. Singh et al. (2013), relatam que usualmente os subcultivos do bambu são feitos entre três e quatro semanas, contudo este experimento sugere a possibilidade de que uma intervenção seja necessária próxima aos 10 dias de cultivo (Figura 2, T3 3G).

No quesito sobrevivência, o tratamento T3 $3 G$ (Figura 2) foi o que apresentou maior número de explantes vivos por mais tempo. Os tratamentos com $4 \mathrm{mg} \cdot \mathrm{L}^{-1} \mathrm{de}$ BAP no meio de cultivo resultaram em maior mortalidade dos explantes, o que pode ser devido a efeito de toxidez aos explantes, pelo excesso de BAP no meio. Resultado semelhante foi relatado por Singh et al. (2012), em que os autores constataram maiores taxas de brotações em meio com doses de BAP abaixo de 3,38 mg.L ${ }^{-1}$. Para Waikhom e Louis (2014), concentrações superiores a $5 \mathrm{mg} . \mathrm{L}^{-1}$ de BAP não são indicadas para as espécies $B$. tulda e $M$. baccifera. Com relação aos tratamentos com 2 mg. $\mathrm{L}^{-1}$ de BAP, o tempo de sobrevivência dos explantes foi similar aos tratamentos com $3 \mathrm{mg} \cdot \mathrm{L}^{-1}$ de BAP, porém a oxidação ocorreu de forma mais rápida.

\section{CONCLUSÃO}

Os resultados obtidos no presente estudo permitiram concluir que:

- O óleo essencial de M. arvensis possui potencial para ser utilizado na desinfestação e inibição do crescimento de fungos e bactérias, dos explantes in vitro obtidos das brotações de bambu utilizadas neste estudo.

- A oxidação interfere significativamente e de forma negativa na sobrevivência dos explantes.

- Os explantes oriundos de gemas axilares, são mais indicados para cultivo in vitro que os oriundos de segmentos nodais.

- O uso de $3 \mathrm{mg} \cdot \mathrm{L}^{-1}$ de BAP no meio de cultivo favoreceu a sobrevivência dos explantes.

- A concentração de $4 \mathrm{mg} \cdot \mathrm{L}^{-1}$ de BAP resultou em possível efeito de toxidez aos explantes neste estudo.

\section{REFERÊNCIAS}

ARAUjo, C. H. P.; CARNEIRO, L. L.; ARAUJO; C. L. P.; SIBOV, S. T. Estabelecimento in vitro de duas espécies de bambu: Dendrocalamus asper (Schultes f.) Backer ex heyne e Bambusa oldhamii Munro. Enciclopédia Biosfera, Goiânia, v.11, n.22, p.1172-1182, dez. 2015. Doi: http://dx.doi.org/10.18677/ Enciclopedia_Biosfera_2015_151

BAREJA, B. G. Bamboo Production and Propagation Methods. [S.I.]: Cropsreview.com. 2010. 19 p. Disponível em: <https://www.doc-developpementdurable.org/file/Arbres-Bois-de-Rapport-Reforestation/FICHES_ARBRES/bambou/ba mbooproduction-and-propagationmethods.pdf>. 
BRUNO, A. N. Biotecnologia II: aplicações e tecnologias. Porto Alegre: Artmed, 2017.

CHAOWANA, P. -Bamboo - A functionally graded composite material. Forest Products Journal. v. 65, n. 3/4, p. 48-53, 2014.

CLARK, L.G., LONDOÑO, X., RUIZ-SANCHEZ, E. Bamboo taxonomy and habitat. In: LIESE, W. \& KÖHL, M. (eds.), Tropical Forestry, Bamboo: the plant and its uses, Springer International Publishing, Switzerland, 2015. p. 1 - 30. Doi: 10.1007/978-3-319-14133-6_3

FILGUEIRAS, T. S.; VIANA, P. L. Bambus brasileiros: morfologia, taxonomia, distribuição e conservação. In: Drumond, P. M.\&Wiedman, G. (Ed.). Bambus no Brasil: da biologia à tecnologia. Rio de Janeiro, RJ: ICH, 2017. p. 10-27.

GADELHA, J. C.; INNECCO, R; ALCANFOR, D. C.; MATTOS, S. H.; FILHO, S. M.; VIEIRA, A. V. Defensivos naturais no tratamento pós-colheita do pedúnculo de melão. Revista Científica Agronômica, v.34, n.1, p.5-10, 2003. Disponível em: $<$ www.ccarevista.ufc.br/site/down.php?arq=14rca34-1.pdf >.

LU, H. F.; CAI, C. J., ZENG, X. S., CAMPBELL, D. E., FAN, S. H., LIU, G. L. Bamboo vs. crops: An integrated emergy and economic evaluation of using bamboo to replace crops in south Sichuan Province, China. Journal of Cleaner Production, v. 177, p. 464-473, 2018. Doi: https://doi.org/10.1016/j.jclepro.2017.12.193

MURASHIGE, T.; SKOOG, F. A. A revised medium for rapid growth and bioassays with tobacco tissue culture. Physiologia Plantarum, v. 15, p. 473-497, 1962.

PEREIRA, G. A.; SANTAELLA, M. B.; ALVES, L. M. S. M.; SILVA, E. C. da. Desinfestação in vitro da bananeira 'Farta velhaco (sub grupo aab)' em diferentes concentrações de cloro ativo. Revista Caatinga, Mossoró, v. 28, n. 4, p. 64-69, 2015. Disponível em: <http://www.scielo.br/pdf/rcaat/v28n4/1983-2125-rcaat-280400064. pdf>. Doi: http://dx.doi.org/10.1590/1983-21252015v28n407rc

RIBEIRO, A. S.; BRONDANI, G. E.; TORMEN, G. C. R.; FIGUEIREDO, A. J. R. de. Cultivo in vitro de bambu em diferentes sistemas de propagação. Revista Nativa, Sinop, v.4, n.1, p.15-18, 2016. Disponível em: <http://periodicoscientificos.ufmt.br/ ojs/index.php/nativa/article/view/3241>. doi: http://dx.doi.org/10.14583/2318-7670. v04n01a04.

SINGH, S. R.; DALAL, S.; SINGH, R.; DHAWAN, A. K.; KALIA, R. K. Micropropagation of Dendrocalamus asper \{Schult. \& Schult. F.\} Backer ex k. Heyne): an exotic edible bamboo. Journal of Plant Biochemistry and Biotechnology, v.21, n.2, p.220-228, 2012. Disponível em: <https://link.springer. com/content/pdf/10.1007\%2Fs13562-011-0095-9.pdf>. Doi: 10.1007/s13562-0110095-9

SINGH, S. R.; SINGH, R.; KALIA, S.; DALAL, S.; DHAWAN, A. K.; KALIA, R. K. Limitations, progress and prospects of application of biotechnological tools in improvement of bamboo - a plant with extraordinary qualities. Physiology and 
Molecular Biology of Plants, v. 19, n. 1, p.21-41, 2013. Disponível em: <https:// www.ncbi.nlm.nih.gov/pubmed/24381435>. doi: 10.1007/s12298-012-0147-1.

SORENG, R. J., PETERSON, P. M., ROMASCHENKO, K., DAVIDSE, G., ZULOAGA, F. O., JUDZIEWICZ, E. J., FILGUEIRAS, T. S., DAVIS, J. I., MORRONE, $O$. A worldwide phylogenetic classification of the Poaceae (Gramineae). Journal of Systematics and Evolution 53: 117-137, 2015. Disponível em: <https://onlinelibrary.wiley.com/doi/abs/ 10.1111/jse.12150>. doi: https://doi.org/10.1111/jse.12150

SOKOVIĆ, M. D.; VUKOJEVIĆ, J.; MARIN, P. D.; BRKIĆ, D. D.; VAJS, V.; GRIENSVEN, L. J. L. D. VAN. Chemical composition of essential oils of Thymus and Mentha species and their antifungal activities. Molecules, v. 14, n. 1, p. 238-249, 2009. Disponível em: <https://www.ncbi.nlm.nih.gov/pubmed/19136911>. doi: 10.33 90/molecules 14010238 .

TORRES, G. R.; SANTOS, P. V. S. DOS; SOUZA, R. A. DE; DANTAS; P. V. P. Efeito da posição de segmentos nodais sobre a contaminação e brotação na micropopagação do bambu. Ciência \& Tecnologia, v. 8, n. 1, p. 1-15, 2016. Disponível em: <http://www.citec.fatecjab.edu.br/index.php/files/article/view/648>.

YEASMIN, L; ALI, M. N.; GANTAIT, S.; CHAKRABORTY, S. Bamboo: an overview on its genetic diversity and characterization. Biotech, v. 201, n. 5, p. 1-11. 2014. Disponível em: <https://www.ncbi.nlm.nih.gov/pmc/articles/PMC4327751/>. doi: 10.1007/s13205-014-0201-5.

WAIKHOM, S. D.; LOUIS, B. An Effective Protocol for Micropropagation of Edible Bamboo Species (Bambusa tulda and Melocanna baccifera) through Nodal Culture. The Scientific World Journal, 8 p. 2014. Doi: http://dx.doi.org/10.1155/2014/345794 